\title{
Sympathetic ophthalmitis following adherent leucoma: A rare association
}

\author{
Perwez Khan, Priyanka Shivhare, Lubna Khan, Ramesh Chand Gupta, \\ Zia Siddiqui
}

\begin{abstract}
Introduction: Sympathetic ophthalmitis is a rare condition. It occurs due to bilateral granulomatous pan uveitis following penetrating trauma or surgery in one eye. Penetrating injury to eye causes exposure of uveoretinal antigens to regional lymph nodes via conjunctival lymphatics thereby inciting delayed $T$ cell hypersensitivity. Case Report: A 35-year-old male patient presented with headache and sudden painless dimunition of vision in both eyes preceded by development of adherent leucoma in left eye due to a perforated bacterial corneal ulcer five months before. Best corrected visual acuity was finger counting close to face in both eyes. Anterior segment examination revealed few keratic precipitates (KPs), 1+ cells and retrolenticular flare in both eyes. Fundus examination revealed exudative retinal detachment in right eye but left eye could not be assessed due to adherent leucoma. B-scan ultrasonography (B-scan)
\end{abstract}

Perwez Khan ${ }^{1}$, Priyanka Shivhare ${ }^{2}$, Lubna Khan ${ }^{3}$, Ramesh Chand Gupta ${ }^{4}$, Zia Siddiqui ${ }^{5}$

Affiliations: ${ }^{1} \mathrm{MS}$, (Ophthalmology), Assistant Professor, Department of Ophthalmology, GSVM Medical College, Kanpur, Uttar Pradesh, India; ${ }^{2}$ MBBS, Junior Resident, Department of Ophthalmology, GSVM Medical College, Kanpur, Uttar Pradesh, India; ${ }^{3} \mathrm{MD}$ (Pathology), Assistant Professor, Department of Pathology, GSVM Medical College, Kanpur, Uttar Pradesh, India; ${ }^{4} \mathrm{MS}$ (Ophthalmology), Professor, Department of Ophthalmology, GSVM Medical College, Kanpur, Uttar Pradesh, India; ${ }^{5} \mathrm{MS}$ (Ophthalmology), Lecturer Department of Ophthalmology, J N Medical College Amu, Aligarh, Uttar Pradesh, India.

Corresponding Author: Perwez Khan, Department of Ophthalmology GSVM Medical College, Kanpur, Uttar Pradesh, India 208002; Ph: +919451875355; Email: perwezkhan@ gmail.com

Received: 02 March 2013

Accepted: 22 May 2013

Published: 01 April 2014 revealed exudative retinal detachment in both eyes. Patient was managed medically with intravenous methyl prednisolone $1 \mathrm{~g}$ for 3 days followed by oral steroids which led to complete resolution of disease process in both eyes. After treatment the best corrected visual acuity was 20/30 in right and 20/80 in left eye. Conclusion: Patients with adherent leucoma subsequent to a perforated corneal ulcer may remain at an increased risk of developing sympathetic ophthalmitis during their lifetime. However, timely medical intervention can lead to good visual prognosis for both exciting as well as the sympathizing eye. Long-term follow-up is necessary as recurrences following cessation of treatment are known to occur.

Keywords: Sympathetic ophthalmitis, Adherent leucoma, Perforated corneal ulcer, Exudative retinal detachment, Methyl prednisolone

\section{How to cite this article}

Khan P, Shivhare P, Khan L, Gupta CR, Siddiqui Z. Sympathetic ophthalmitis following adherent leucoma: A rare association. International Journal of Case Reports and Images 2014;5(4):273-276.

doi:10.5348/ijcri-201456-CR-10367

\section{INTRODUCTION}

Sympathetic ophthalmitis is defined as bilateral granulomatous pan uveitis that follows penetrating trauma or surgery in one eye [1]. An incidence of $0.19 \%$ following penetrating injury and $0.007 \%$ following intraocular surgery has been reported [2]. It is believed to be an autoimmune reaction to uveal antigen that involves a cell mediated immune response [3]. The common denominating factor in majority of cases is presence of a 
penetrating injury in which wound healing is complicated by incarceration of iris, ciliary body and choroid $[3,4]$. It affects both eyes and usually occurs between two weeks to three months after trauma but it can extend up to many years, 80\% cases occur within three months and 90\% within a year [5]. It has an insidious onset with progressive course and exacerbations. The classical description of signs include granulomatous mutton fat keratic precipitates (KPs), anterior chamber and vitreous inflammations with or without yellow white lesions in the retinal periphery. Other fundal lesions like retinal detachment, papillitis, optic atrophy and vasculitis are reported uncommonly with anterior segment inflammation [6]. Cases who present early with only fundus lesions are usually associated with minimal or no anterior segment inflammation, this atypical form of sympathetic ophthalmitis is termed posterior sympathetic ophthalmitis. The posterior form of disease is encountered in $5 \%$ of all cases of sympathetic ophthalmitis, is invariably accompanied by late development of anterior uveitis. It is neither clinically nor pathologically different from classical form [7].

\section{CASE REPORT}

A 35-year-old male patient presented to our institution with complaints of blurring of vision in both eyes and headache for 15 days. The patient had a history of perforated bacterial corneal ulcer five months before in his left eye leading to adherent leucoma. Best corrected visual acuity in both eyes was finger counting close to face. Anterior segment examination of both eyes showed few KPs, +1 cells and mild retrolental flare while left eye had adherent leucoma in addition to above findings (Figure 1). On fundus examination of right eye exudative retinal detachment and few choroidal lesions over fundus were detected (Figure 2), while left eye

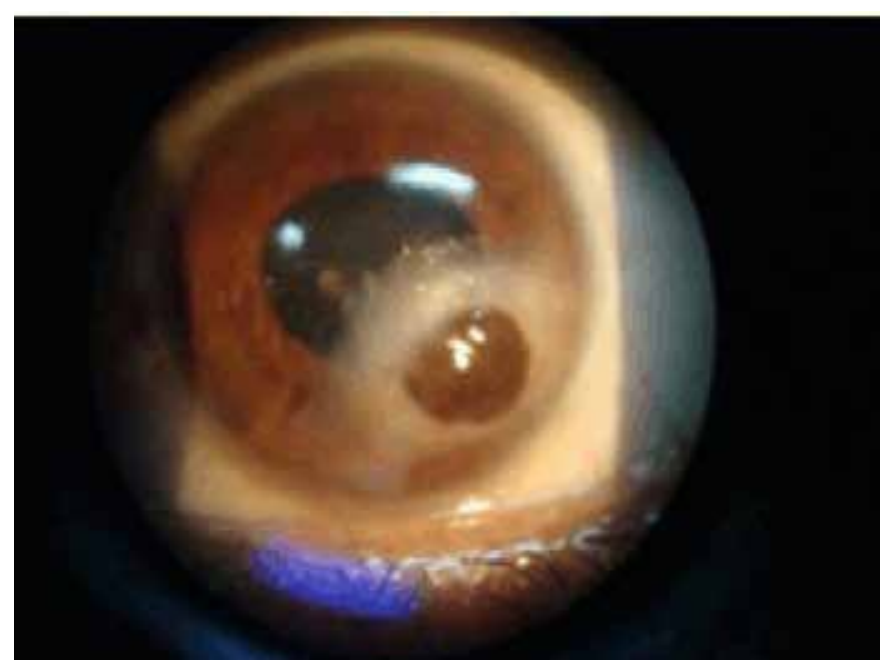

Figure 1: Slit Lamp photograph of left eye (exciting eye) of patient showing adherent leucoma. fundus could not be accessed due to adherent leucoma. The intraocular pressure was $12 \mathrm{mmHg}$ in both eyes. The systemic evaluation did not reveal any evidence of a focus of infection, vitiligo, alopecia, dysacousia or meningeal signs. The erythrocyte sedimentation rate (ESR), chest X-ray, enzyme-linked immunosorbent assay (ELISA) for toxoplasma, venereal disease research laboratory test (VDRL) test and audiometry were within normal limits.

Ultrasonography for the posterior segment revealed retinal detachment in both eyes (Figures 3 and 4). The fluorescein angiogram of the right eye showed multiple hyperfluorescent spots at the level of the retinal pigment epithelium in the venous phase which persisted in the late phase. In addition, there was coalescence of the dye in the area of the exudative detachment. Based on the typical history and clinical signs, a diagnosis of sympathetic ophthalmitis was made and the patient was initiated on high dose intravenous steroids with 1 gram methyl prednisolone for three days followed by oral steroids 50 grams in single dose for one week which was then slowly tapered over the next three months. Resolution of the exudative detachment with recovery of best corrected visual acuity to 20/200 in both eyes occurred after 72 hours following the initiation of intravenous steroids (Figure 5).

At one week patient became asymptomatic with a visual acuity of 20/60 in right eye and 20/80 in left eye with no evidence of disease activity. Visual acuity improved to 20/30 in right eye and 20/80 in left eye at one month follow-up and remained the same with no sign of relapse.

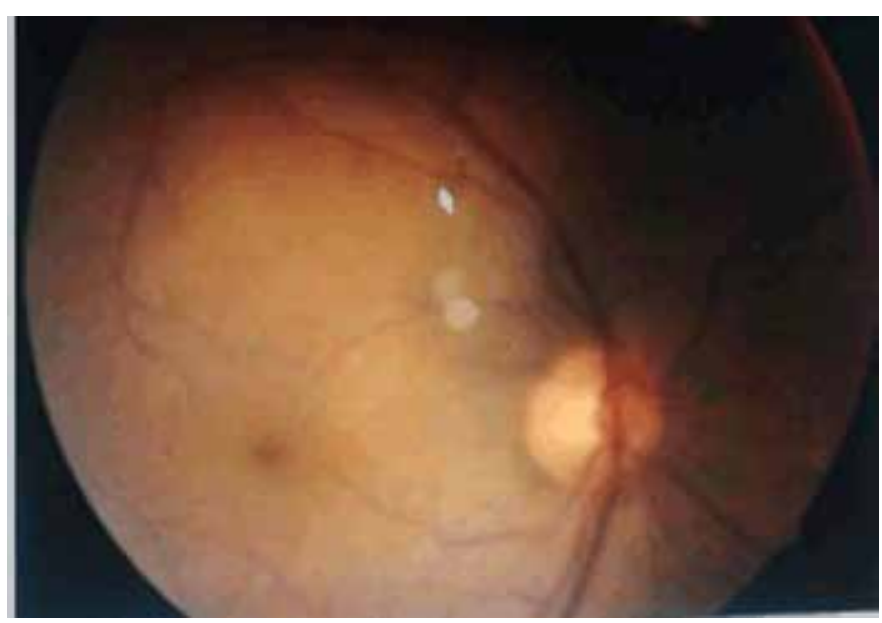

Figure 2: Fundus photograph of right eye (sympathising eye) showing exudative retinal detachment.

\section{DISCUSSION}

Sympathetic ophthalmitis may occur with varying degree of severity, from a mild anterior uveitis or peripapillary choroiditis to a severe panuveitis with mutton fat keratic precipitates or posterior uveitis. 


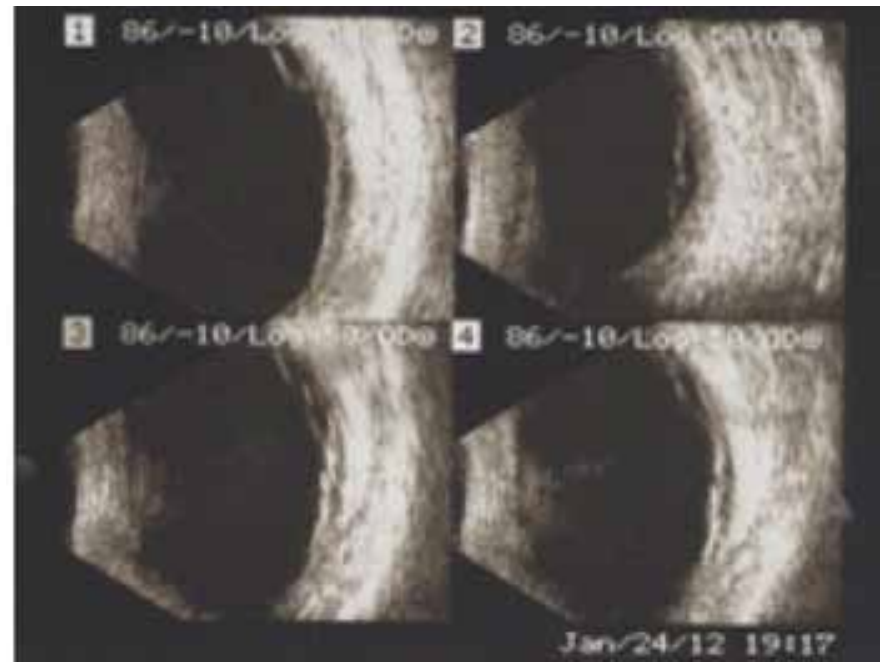

Figure 3: Ultrasonography B-scan of right eye showing exudative retinal detachment.

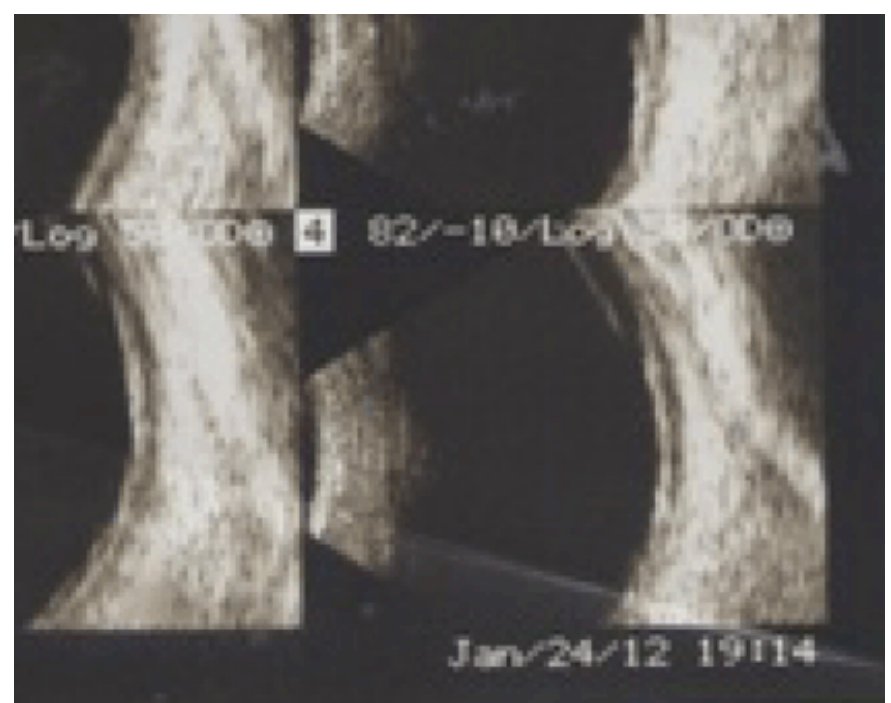

Figure 4: Ultrasonography B-scan of left eye showing exudative retinal detachment.

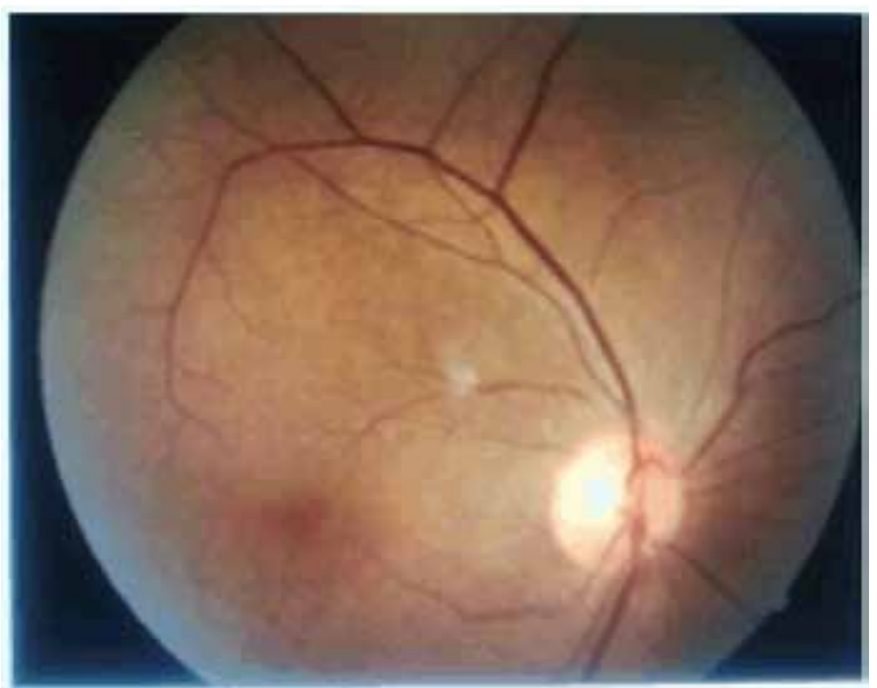

Figure 5: Fundus photograph right eye of same patient after 10 days of treatment with steroids showing complete resolution of retinal detachment.
Some cases with sympathetic ophthalmitis may present with only fundal lesions with no or minimal anterior segment inflammation. Sympathetic ophthalmitis may be accompanied by headache, pleocytosis of spinal fluid, dysacousis, tinnitus, alopecia, poliosis and vitiligo [8]. The systemic association is similar to those seen in Vogt-Koyanagi-Harada (VKH) syndrome [8]. Diagnosis of posterior sympathetic ophthalmitis was rendered in the present case as patient had signs and symptoms of posterior segment involvement with minimal anterior segment inflammation along with history of perforated corneal ulcer five months back leading to adherent leucoma. Sympathetic ophthalmitis is not easily diagnosed. Only 20\% of clinically suspected cases are confirmed by histopathologic evaluation [4]. The history of a penetrating injury or surgery and bilateral ophthalmitis serve as basis for diagnosis, along with typical ocular and associated findings, fundus fluorescein angiography and B-scan may assist in diagnosis.

The role of a perforated corneal ulcer in the pathophysiology of sympathetic ophthalmitis is to provide intraocular uveoretinal antigens an access to the regional lymph nodes via conjunctival lymphatics [3]. This may cause a sensitizing reaction to these antigens and set up a delayed $\mathrm{T}$ cell hypersensitivity, which may be responsible for the disease process [3]. Exciting eye with hopeless visual prognosis should be enucleated within two weeks after injury to prevent autoimmune reaction [8]. Once the disease has developed, enucleation of the exciting eye may not prevent the inflammation in the sympathizing eye [9]. An attempt to preserve the eye should be made if good visual prognosis is expected because sometimes in patients with sympathetic ophthalmitis, the exciting eye can have better visual prognosis than the sympathizing eye [10]. Topical corticosteroids eye drops and cycloplegics decrease inflammation, formation of medications can be used. It requires long term treatment and follow-up because recurrent episodes after cessation of treatment can occur [11].

\section{CONCLUSION}

Patients with adherent leucoma subsequent to a perforated corneal ulcer may remain at an increased risk of developing sympathetic ophthalmitis during their lifetime. However, timely medical intervention can lead to good visual prognosis for both exciting as well as the sympathizing eye. Long-term follow-up is necessary as recurrences following cessation of treatment are known to occur.

$$
* * * * * * * * *
$$

\section{Author Contributions}

Perwez Khan - Conception and design, Acquisition of data, Analysis and interpretation of data, Drafting the article, Critical revision of the article, Final approval of the version to be published 
Priyanka Shivhare - Conception and design, Acquisition of data, Analysis and interpretation of data, Drafting the article, Critical revision of the article, Final approval of the version to be published

Lubna Khan - Conception and design, Acquisition of data, Analysis and interpretation of data, Drafting the article, Critical revision of the article, Final approval of the version to be published

Ramesh Chand Gupta - Analysis and interpretation of data, Critical revision of the article, Final approval of the version to be published

Zia Siddique - Analysis and interpretation of data, Critical revision of the article, Final approval of the version to be published

\section{Guarantor}

The corresponding author is the guarantor of submission.

\section{Conflict of Interest}

Authors declare no conflict of interest.

\section{Copyright}

(C) Perwez Khan et al. 2014; This article is distributed under the terms of Creative Commons attribution 3.0 License which permits unrestricted use, distribution and reproduction in any means provided the original authors and original publisher are properly credited. (Please see www.ijcasereportsandimages.com/copyright-policy.php for more information.)

\section{REFERENCES}

1. Müller-Hermelink HK, Kraus-Mackiw E, Daus W. Early stage of human sympathetic ophthalmia.
Histologic and immunopathologic findings. Arch Ophthalmol 1984;102(9):1353-7.

2. Liddy L, Stuart J. Sympathetic Ophthalmia in Canada. Can J Ophthalmol 1972;7(2):157-9.

3. Rao NA, Robin J, Hartmann D, Sweeney JA, Marak GE Jr. The role of the penetrating wound in the development of sympathetic ophthalmia: Experimental observations. Arch Ophthalmol 1983;101(1):102-4.

4. Marak GE Jr. Recent advances in sympathetic ophthalmia. Surv Ophthalmol 1979;24(3):141-56.

5. Lubin JR, Albert DM, Weinstein M. Sixty-five years of sympathetic ophthalmia. A clinicopathologic review of 105 cases (1913--1978). Ophthalmology 1980;87(2):109-21.

6. Nussenblatt RB. Sympathetic Ophthalmia. In: Nussenblatt RB, Whitcup SM (eds). Uveitis Fundamentals and Clinical Practice. 3rd ed. USA: Elsevier 2004:311-23.

7. Woods AC. Sympathetic ophthalmia. Arch Ophthal 1936;19:9-15.

8. Rao NA, Marek GE Jr. Sympathetic uveitis. In: Yanoff M, Duker JS (eds). Ophthalmology 3rd ed China: Elsevier 2009;862.

9. Kilmartin DJ, Dick AD, Forrester JV. Prospective surveillance of sympathetic ophthalmia in the $\mathrm{UK}$ and Republic of Ireland. Br $\mathrm{J}$ Ophthalmol 2000;84(3):259-63.

10. Winter FC. Sympathetic uveitis: A clinical and pathologic study of the visual result. Am J Ophthalmol 1955;39(3):340-7.

11. MakleyTAJr, Azar A. Sympathetic ophthalmia. Alongterm follow-up. Arch Ophthalmol 1978;96(2):25762.
Access full text article on other devices

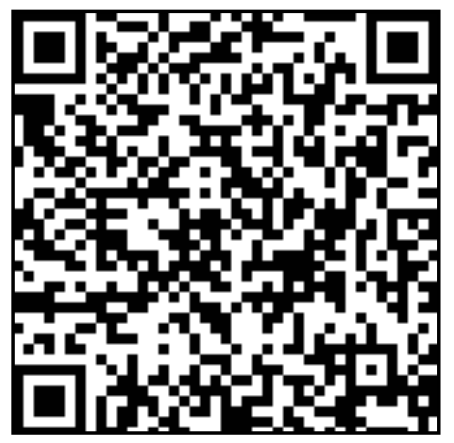

Access PDF of article on other devices

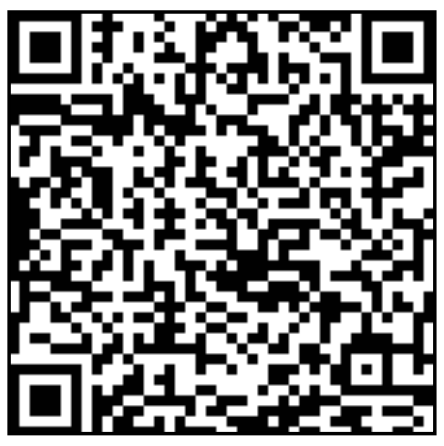

